Comparative Philosophy Volume 2, No. 2 (2011): 04-22

Open Access / ISSN 2151-6014

www.comparativephilosophy.org

\title{
ANALYTIC AND CONTINENTAL PHILOSOPHY, SCIENCE, AND GLOBAL PHILOSOPHY
}

\author{
RICHARD TIESZEN
}

\begin{abstract}
Although there is no consensus on what distinguishes analytic from Continental philosophy, I focus in this paper on one source of disagreement that seems to run fairly deep in dividing these traditions in recent times, namely, disagreement about the relation of natural science to philosophy. I consider some of the exchanges about science that have taken place between analytic and Continental philosophers, especially in connection with the philosophy of mind. In discussing the relation of natural science to philosophy I employ an analysis of the origins of natural science that has been developed by a number of Continental philosophers. Awareness and investigation of interactions between analytic and Continental philosophers on science, it is argued, might help to foster further constructive engagement between the traditions. In the last section of the paper I briefly discuss the place of natural science in relation to global philosophy on the basis of what we can learn from analytic/Continental exchanges.
\end{abstract}

Keywords: analytic philosophy, Continental philosophy, natural science, sciences of mind, global philosophy, Dao-De-Jing, Buddhism

There are many references in the philosophical literature to the division between analytic and Continental philosophy but it is not easy to provide a simple formulation of what it is that distinguishes these approaches to or styles of philosophy. There have been significant subdivisions within what has been considered analytic philosophy, such as that between formal philosophy, ordinary language philosophy, and conceptual analysis, and there have of course also been many variations within the general grouping of Continental philosophy, extending from eidetic phenomenology, existential phenomenology, existentialism, structuralism and semiotics, and neoFreudian analysis to deconstruction. Philosophers who have written about the split between the analytic and Continental traditions have often focused on the work of particular figures who seem to embody much of what is involved in the division. In The Origins of Analytic Philosophy, for example, Michael Dummett looks to Frege

TIESZEN, RICHARD: Professor, Department of Philosophy, San Jose State University, USA. Email: richard.tieszen@sjsu.edu 
and Husserl and holds that Frege took a turn into the philosophy of language but that Husserl did not, thus initiating a split in modern philosophy. Michael Friedman, to take another example, writes a book entitled A Parting of the Ways in which he focuses on Carnap, Cassirer, and Heidegger.

Over the years I have heard or read a host of characterizations of the two traditions, such as the following: Analytic philosophy strives for clarity, exactness, precision and Continental philosophy does not. Continental philosophy instead tends toward the use of poetic or dramatic language. The methodology of analytic philosophy is argumentation while Continental philosophy, if it has a methodology at all, is concerned with description or narrative or literary quality. Analytic philosophy is, in many domains, reductionistic in nature and Continental philosophy is not. Analytic philosophy tends to be ahistorical while Continental philosophy does not. Analytic philosophers seek to naturalize or formalize or mathematize but Continental philosophers do not. Analytic philosophers have, more often than not, taken the 'linguistic turn', while this is not true of Continental philosophers. The general idea of the linguistic turn is that, instead of analyzing $X$ (e.g., Being or obligation) we are to analyze the language of $X$. I have also heard it said that analytic philosophy places a premium on reason but Continental philosophy does not. Continental philosophy is instead concerned with basic issues of human existence, such as anxiety, authenticity, death, boredom, identity, and so on.

One has to be careful about all of these characterizations. I do not think that any one of them, as it stands, is accurate. In this paper I want to consider what I think is one source of disagreement that does run fairly deep in dividing the traditions, especially in connection with efforts in recent times to 'naturalize' philosophy in one way or another. Although the contours of the issue are shaped in certain ways by the division between analytic and Continental philosophy, it is an issue that certainly has implications for the broader vision of comparative philosophy that takes in cultures and systems of thinking from around the world. The source of disagreement I have in mind concerns the relationship of science, especially natural science, to philosophy. The issue might be formulated in different ways: Is natural science to be a model for philosophy or not? Is it, in some sense, foundational, so that philosophy should be measured against it or, rather, is philosophy, properly conceived, a foundation for science? Is natural science limited and one-sided as a model for philosophy or does it represent just the sort of regimentation we need in philosophy? One might put it in this way: Is natural science a condition for the possibility of legitimate philosophy or is philosophy in some sense a condition for the possibility of natural science? What is the proper way to think about the relation of philosophy to natural science? It is these kinds of questions, I think, that have a direct bearing on comparative philosophy in a broad sense, and on the prospects for constructive engagement between widely varying philosophical traditions.

Several major Continental philosophers have thought deeply and carefully about natural science, while others have had little to say about it one way or the other. Those Continental philosophers who have presented extensive critiques of the sciences have typically argued that philosophy or metaphysics provides a foundation 
in some sense for the sciences, while many (but not all) analytic philosophers are inclined to a kind of scientism according to which our best efforts to understand reality and knowledge are to be found in the natural sciences. Just think of the various pretensions of philosophers, they might say, that have been undermined by good solid scientific work. Think of the revelations that have been made possible by natural science that would not have been possible on the basis of philosophy alone.

In most of this paper I compare some ideas on the relation of natural science to philosophy that have emerged from the traditions of analytic and Continental philosophy. It will of course not be possible to do justice to the many strands of thinking about natural science in analytic and Continental philosophy. One could ask general questions, for example, about the understanding or knowledge of Being (or non-Being) in natural science, or one could focus on the work of particular philosophers in either tradition. In order to make the project somewhat more manageable in the space available here I will focus on the philosophy of mind in particular, and especially on issues about human consciousness. In the final sections of the paper I make some remarks on how constructive engagement between different philosophical traditions in the world might benefit from what has transpired in the analytic and Continental encounters over the relation of natural science to philosophy. These other traditions might of course also inform the ongoing disputes that seem to separate analytic from Continental philosophy.

\section{ILLUSTRATIVE QUOTATIONS ON THE PLACE OF SCIENCE IN ANALYTIC AND CONTINENTAL PHILOSOPHY}

A number of the characterizations of the difference between analytic and Continental philosophy that I mentioned above, especially those centering around clarity, precision, use of argumentation, reductionism, formalization, mathematization, and reason, are I think directly related to this issue of how we are to view the relation of philosophy to natural science. Let me provide a few illustrative quotations on both sides of the issue from some major figures in philosophy, starting with some early comments of Martin Heidegger and Rudolph Carnap that express an animosity that persisted for many years. Heidegger wrote extensively on science and technology, and many philosophers know his remark that "science does not think". Already in his 1929 lecture "What Is Metaphysics?" Heidegger says that

Science would like to dismiss the nothing with a lordly wave of the hand. But in our inquiry concerning the nothing it has by now become manifest that scientific existence is possible only if in advance it holds itself out into the nothing. It understands itself for what it is only when it does not give up the nothing. The presumed soberness of mind and superiority of science become laughable when it does not take the nothing seriously. Only because the nothing is manifest can science make beings themselves objects of investigation. Only if science exists on the base of metaphysics can it advance further in its essential task, which is not to amass and classify bits of knowledge but to disclose in ever-renewed fashion the entire region of truth in nature and history. 
Metaphysics is the basic occurrence of Dasein. It is Dasein itself. Because the truth of metaphysics dwells in this groundless ground it stands in closest proximity to the constantly lurking possibility of deepest error. For this reason no amount of scientific rigor attains to the seriousness of metaphysics. Philosophy can never be measured by the standard of the idea of science.

In his infamous paper "The Elimination of Metaphysics Through Logical Analysis of Language" (1932) in which he attacks the lecture of Heidegger from which I just quoted, alleging that it is filled with meaningless pseudo-sentences, the logical positivist Carnap says the following:

The development of modern logic has made it possible to give a new and sharper answer to the question of the validity and justification of metaphysics...In the domain of metaphysics, including all philosophy of value and normative theory, logical analysis yields the negative result that the alleged statements in this domain are entirely meaningless.

But what, then, is left over for philosophy, if all statements whatever that assert something are of an empirical nature and belong to factual science? What remains in not statements, nor a theory, nor a system, but only a method: the method of logical analysis. It is the indicated task of logical analysis, inquiry into logical foundations, that is meant by 'scientific philosophy' in contrast to metaphysics.

In The Logical Syntax of Language (1934), Carnap goes on to claim that

Philosophy is to be replaced by the logic of science - that is to say, by the logical analysis of the concepts and sentences of the sciences, for the logic of science is nothing other than the logical syntax of the language of science.

The engagement between analytic and Continental philosophy that developed around these kinds of claims was not often not very constructive.

An interesting response to Carnap, in turn, can be found in the remarks of one of the greatest logicians of all time, Kurt Gödel. Gödel, who attended meetings of the Vienna Circle on a regular basis, says that

Mathematical logic should be used by more nonpositivistic philosophers. The positivists have a tendency to represent their philosophy as a consequence of logic -- to give it scientific dignity. Other philosophers think that positivism is identical with mathematical logic, which they consequently avoid. (Kurt Gödel, as cited by Hao Wang in Wang 1996, 174.)

It is known that Gödel began to study Husserl's work in $1959 .{ }^{1}$ Writing about his interest in Husserl in a lecture manuscript from 1961, "The Modern Development of the Foundations of Mathematics in the Light of Philosophy", Gödel says

${ }^{1}$ For more on Gödel and Husserl, see Tieszen 2011. 
... not only is there no objective reason for the rejection of [phenomenology], but on the contrary one can present reasons in its favor.

Gödel comments on one of the central concepts in Husserlian phenomenology, the concept of intentionality:

One fundamental discovery of introspection marks the true beginning of psychology. This discovery is that the basic form of consciousness distinguishes between an intentional object and our being pointed (directed) toward it in some way (willing, feeling, cognizing). There are various kinds of intentional object. There is nothing analogous in physics. This discovery marks the first division of phenomena between the psychological and the physical. (Wang 1996, 169)

Finally, I note a remark by Quine $(1960, \S 45)$ about this same concept of intentionality:

The Scholastic word 'intentional' was revived by Brentano in connection with the verbs of propositional attitude and related verbs [such as] 'hunt', 'want', etc. The division between such idioms and the normally tractable ones is notable. We saw how it divides referential from non-referential occurrences of terms. Moreover it is intimately related to the division between behaviorism and mentalism, between efficient cause and final cause, and between literal theory and dramatic portrayal.

One may accept the Brentano thesis either as showing the indispensability of intentional idioms and the importance of an autonomous science of intention, or as showing the baselessness of intentional idioms and the emptiness of a science of intention. My attitude, unlike Brentano's, is the second.

It would of course be possible to provide many more quotations to show that differences over the relationship of (natural) science to philosophy continue to divide analytic from Continental philosophers. It is an issue that has at times clearly interfered with constructive engagement between the two traditions. Skirmishes of this type even receive a lot of attention in the popular press on occasion, as happened several years ago with the so-called 'Sokal hoax', which led to the book by Alan Sokal and Jean Bricmont titled Fashionable Nonsense: Postmodern Intellectuals' Abuse of Science and to the more recent Beyond the Hoax: Science, Philosophy and Culture by Sokal.

\section{PHILOSOPHY OF MIND AS AN EXAMPLE}

The relationship of science to philosophy in analytic and Continental philosophy is a large issue. I would like to limit the scope of the discussion somewhat, as I indicated, by considering as an example the differing views in the case of the philosophy of mind, especially as this concerns human consciousness. The twentieth century saw a succession of efforts, championed by many analytic philosophers, to develop a 
natural science of the human mind. The natural sciences involved were of different types but what they had in common, as I will argue in a moment, is a set of features that has to be in place if natural science is to exist at all. Neuroscience played the central role in identity theory, while behaviorists focused instead on trying to develop a science at the level of observable human behavior, dispositions to behave, and operant conditioning. Since the time that identity theory emerged there have been various forms of neuroscientific reductionism. From a different direction, linguistics was being linked by some thinkers with the effort to develop a natural science of the mind. Functionalism then emerged in response to problems with behaviorism and identity theory. Computational or Turing machine functionalism was the main contender. It was at this stage that computer science entered into the effort to develop a natural science of the mind. This approach itself splintered into 'symbolic', serial models of minds, parallel distributed processing (connectionist) models of minds, or various hybrids of such models. At an even later stage such models were criticized for their lack of biological realism. Evolutionary biology, it was argued, should figure into any science of the mind. Perhaps we are, for example, 'Darwin machines' of some kind.

Every one of these efforts to develop a (natural) science of the mind in the twentieth century, however, was faced with the same problem: leaving out or failing to do justice to consciousness. This "problem of consciousness" has been invariant through all of these positions, as well as a number of other positions, and at present it is just as troublesome for natural science as it has ever been. From the point of view of a number of Continental philosophers, however, it is obvious why the problem of consciousness has persisted throughout all of the efforts to develop a natural science of the mind. I think that some of Husserl's work, in particular, makes this especially clear. In order to see why the problem has persisted I will start by considering some of the conditions that have to be met in order for modern natural science to be possible.

\section{THE ORIGINS OF MODERN NATURAL SCIENCE}

Science, as we understand it today, did not always exist. There are deep analyses of the origins of modern natural science, especially from the side of some Continental philosophers. What we need to do is to consider some of the general features involved in our understanding the world on the basis of the natural sciences. In speaking of 'natural sciences' in this paper I have in mind primarily what have been called the 'hard' sciences, such as the various areas of mathematical physics, chemistry, computer science, and the like. A distinction is sometimes drawn between the natural sciences and the human sciences. There are features of the natural sciences that are not always present in sciences or areas of investigation that focus on human beings and their activities, such as the social sciences. The following aspects of our experience, aspects that can overlap and condition one another, are involved in making the natural sciences possible: 
(1) The central epistemic idea of empiricism or naturalism is that all knowledge is derived from sensory (external or outer) experience. Evidence in natural science is based on sensory experience. Natural sciences often seek to determine causal relations and proffer causal explanations in domains of inquiry that are based on sensory experience of objects and processes in nature, although there are some anomalies about this in domains such as quantum physics. Hypotheses in natural science need not always be causal. They can be merely correlational.

(2) The distinction between quantitative and qualitative aspects of our experience of the world, and the use of calculational or mechanical techniques with the quantitative aspects.

(3) The distinction between formal and "material" aspects of our thinking and understanding (where calculation can also be used with the formal aspects) along with a related distinction between form and meaning.

(4) The role of idealization and abstraction.

(5) The related distinction between the universal and the particular, or between the general and the specific, with the idea that natural science is to seek generalities, uniformities, or universal laws concerning natural phenomena in different domains.

(6) The fact that there are prereflective and immediate forms of experience and also more reflective, mediate forms of experience.

(7) The fact that science requires 'objectivity', so that some way of separating the objective from the subjective is called for by modern science.

I will not say much here about point (1). Hypotheses of natural science are sometimes correlational and not causal, and some theories of natural science are mostly, if not entirely, descriptive in nature. The claim that that all knowledge is derived from sensory (external or outer) experience, however, establishes a baseline for natural sciences. Sense experience is perfectly appropriate for and is required by empirical sciences. Concerning point (2), one of the central features involved in many of the natural sciences is calculative thinking. Not all types of thinking appear to be calculative but calculative thinking is a condition for the possibility of many of our sciences. One simply cannot engage in vast domains of natural science without calculative methods and concepts. It can of course take a great deal of training and specialization to master and develop these methods and concepts, and the methods and concepts will themselves take on more or less value as a function of how much work they do, the range of their application, how efficient they are, and so on. Calculative thinking requires that we be able to distinguish quality from quantity in phenomena. One must be able to quantify phenomena to make them amenable to calculational techniques. This emphasis on the mathematization of experience is clearly present at the beginning of modern natural science in the distinction between so-called primary and secondary qualities. Such a distinction can be found in the work of Galileo, Descartes, Locke, and others. It has been argued that the distinction is present even in ancient Greek philosophy. In Galileo's work, for example, number, shape, magnitude, position, and motion are taken to be primary qualities and colors, tastes, smells, and warmth/cold to be secondary qualities. The former properties are seen as objective features of experience while the latter are viewed as subjective. 
Indeed, the primary qualities are just those that are mathematizable and, in Galileo's view, are absolute and immutable, while the secondary qualities are sensory, relative, and fluctuating. Knowledge is concerned with primary qualities, but opinion and illusion are generally associated with secondary qualities. One might hold that the primary qualities inhere in the objects themselves while secondary qualities do not. The primary qualities are tightly linked with third-person, empirical observation. They are the "objective" features of the world of causes and effects.

The features of quantification and calculation are attended by the feature involved in scientific understanding mentioned in point (3): the shift from "contentual" or "material" aspects of thinking and understanding to formal aspects. The quantifiable aspects of our experience are represented in mathematical and logical formulas. Mathematics, mathematical physics, chemistry, engineering, and many of the other pure and applied sciences require that we discern the form or structure of phenomena. In attempting to determine the form or structure of a phenomenon a kind of formal abstraction takes place. What we abstract from, what is not needed, is what I have called the 'content' or 'matter' associated with the phenomenon. One of the interesting outgrowths of mathematization is that once we have worked out the appropriate mathematics for the scientific treatment of a phenomenon we can often mechanize the mathematics.

What we have said thus far is that with the modern understanding of the world in natural science there is often a focus on quantitative aspects of our experience, where computational techniques are used with the quantitative features abstracted. The understanding of the world in natural science, in a similar vein, involves a shift to formal or structural features of experience in which we abstract from content or certain aspects of meaning. These shifts, as indicated in point (4), are attended by a kind of idealization. Everyday experience is inexact and imprecise in a variety of ways. With the shift to quantification and formalization we obtain a kind of precision and exactness that is otherwise not available to us. This move toward the more exact and precise involves us in various idealizations. We leave behind some of the complexity and richness but also the imperfection of the plenum of everyday experience. The scientific understanding of the world is thus typically an understanding in which various idealizations of the world are at work.

Points (2), (3) and (4) are closely related to some issues about the language of science and the language of philosophy. It is not possible to quantify and calculate in just any language. The languages in which we quantify and calculate in many of the natural sciences are exact, formal languages. In the sciences one attempts to eliminate ambiguity and vagueness. This is a prerequisite for testing and confirming theoretical hypotheses, and for making predictions. If we cannot minimize the number of possible interpretations of the expressions of the language of a science then we cannot obtain definite results that can be corroborated. Scientific language is thus generally characterized by a kind of exactness and rigor that we do not find outside of the sciences.

According to point (5), natural science requires that we be able to distinguish universal from particular features in our experience. Natural science is all about 
finding regularities, generalizations, or lawlike features of the world on the basis of our particular sensory experiences. Points (2), (3), and (4) are all involved in making this possible.

As I have been indicating, the understanding of the world provided by natural science involves various kinds of abstraction. It requires us to abstract from a larger whole, i.e., the whole of our experience. It is common in certain theories of wholes and parts to distinguish "pieces" (independent parts) from "moments" (nonindependent parts). What makes a part of a whole a piece is just that it can exist independently of the whole of which it is a part, while this is not possible in the case of moments. Moments are abstractions that are "founded" on larger given wholes. Now quantification, formalization, generalization, variation and the like are moments of our experience. They are founded on our experience as a whole, where this experience also includes qualitative, contentual, non-calculational, "meaningful", referential, and particular or specific aspects. The modern understanding of the world in natural science would therefore count as a founded understanding of the world. This means that there is a deeper, founding whole on which it depends and of which it is a part. In a book that is of some interest for comparative philosophy, The Crisis of the European Sciences and Transcendental Phenomenology, Edmund Husserl calls the deeper founding stratum of everyday practices and perception the "lifeworld" (Lebenswelt). This notion of the lifeworld had a significant impact on subsequent work in the Continental tradition of philosophy. A conception such as the lifeworld can also be found in the work of other philosophers. Wilfrid Sellars, for example, distinguishes what he calls the 'manifest image' of the world from the "scientific image". Sellars would probably be considered by most people, by the way, to be an analytic philosopher.

This leads us to point (6). The founded understanding of the world that is present in natural science and modern technology requires the various kinds of reflective activities we have been discussing. The modern scientific understanding of the world is, I would like to argue, a more reflective form of understanding that involves us in various abstractions and idealizations. There are, however, also prereflective and more immediate forms of understanding or awareness. These are forms of understanding or awareness that do not involve all of the abstractions and scientific theorizing that are in the background of the understanding of the world in natural science.

To abstract features of our experience is not itself to be engaged in experience in the same way that we would be were we not abstracting. Abstracting features of experience already requires, as we said, taking a more reflective stance on our experience. Indeed, we might draw a general (albeit relative) distinction between reflective and prereflective modes of experience. Prereflective modes of experience would be more immediate forms of experience. They would not involve the kind of mediation that attends higher levels of generalization, abstraction, imaginative variation, and theory construction. So the features we abstract from our experience are founded on some larger whole of experience. As Husserl says, there is a founding level of experience and then also founded forms of experience. The natural sciences 
must count as providing us with a founded form of experience. Modern natural science is built up over time out of abstractions that involve more reflective, mediate and theoretical stances on our experience. There are, as it were, layers of thinking, directedness, and experience. Various Continental philosophers have pointed out that there can be and has been lifeworld experience without natural science.

What this higher-level interpretive scheme yields, however, is just the kind of distinction noted in point (7). Points (2)-(6), which are concerned with quantification, calculation, formalization, idealization, exactness, precision, and generalization, all involve a more reflective, mediated perspective on the world. Along with point (1), they are all features that allow us to separate what is objective from what is subjective. The scientific understanding of the world involves us in a higher degree of objectification of the world. It is thanks to these features that other commonly recognized aspects of objectivity are possible, such as intersubjective agreement on methods and results and repeatability of calculations, experiments, procedures, and the like. As mentioned earlier, it was the intention of Galileo and other founders of modern natural science to distinguish what was absolute and immutable from what was relative, fluctuating and due solely to subjective sensory experience. Knowledge is then supposedly concerned with the former characteristics and the rest is a matter of opinion and illusion. It is a corollary of our earlier analysis that this search for "objective" characteristics itself involves a kind of abstraction from our experience. The point is precisely to excise the subjective aspects of experience. What we obtain with natural science is a kind of objectivity that would otherwise be lacking in our epistemic enterprises. We can leave behind the inner sensings, feelings, thoughts, and subjective perspectives and focus on the outer observable phenomena that would, in principle, be available to all. What natural science yields is just the third-person stance on the world. In short, the intention behind it is precisely to abstract from human subjectivity, to minimize subjectivity and maximize objectivity.

With these seven points we can therefore specify some of the central elements of the scientific understanding of nature, an understanding that has set the tone for a lot of thinking in analytic philosophy. The features I have discussed, taken as a whole, give us a particular perspective on the world. They provide a way of interpreting the world. Science reveals the world to us in a certain way. It is by these means that we approximate an exactness, clarity, and distinctness in our knowledge that is not part of our everyday, informal understanding of the world. Indeed, an interpretive scheme comprised of these components has a normative character. In light of the successes of mathematical natural science and modern technology we might come to believe that we should quantify, formalize, and idealize. This kind of interpretive scheme is routinely applied to nature and everything in nature. We can see how it is at work in the various natural sciences. It conditions what is revealed to us and the revelations of natural science have indeed been very successful, yielding predictions, control, and hence a remarkable kind of power over nature in many domains. Great advances in science and technology have been made on many fronts.

Before moving on to the next section, it should be noted that I do not mean to deny that there are sciences that lack some of the features mentioned in the seven 
points above. Several of the points are necessary conditions for natural science but some parts of natural science might be non-quantitative, might be primarily descriptive and not focused on providing causal explanations, or might not engage formalization to any significant extent. I will make some further comments about this below.

\section{LIMITATIONS ON NATURAL SCIENCE IN PHILOSOPHY OF MIND}

The distinctions that lie behind the empiricist, scientific worldview and modern mechanism that are indicated in our seven points allow us to separate the subjective from the objective. They are in fact used for just this purpose. With quantification, calculation, formalization, idealization and exactness we obtain intersubjective agreement on methods and results, including repeatability of calculations, experiments, procedures, and predictions. We obtain a kind of objectivity, and objectivity is what we seek everywhere in the modern sciences.

Now here is the point that is made by a number of Continental philosophers: what happens when this kind of interpretive scheme is turned back around on human beings in particular? What happens is that the very methods required in order for the natural sciences to be possible are methods that abstract away from subjectivity, consciousness, intentionality, and other features of experience itself. Positions that have been favored by many analytic philosophers, such as behaviorism, computational functionalism, connectionism, and neuroscientific reductionism about the mind, all tend toward or even promote a kind of eliminativism about consciousness, intentionality, qualia, and the like. It is not surprising that what is "revealed" to us is that the nature of human being is quantifiable, formalizable or computational.

When we turn natural science back around on ourselves we thus find that, true to our intentions to eliminate human subjectivity, we have eliminated human subjectivity with all of its complexity and detail. Instead we have a purely objectified subject, merely the outer shell as it were. Consciousness, the very essence of subjectivity, disappears. At earlier stages in the development of the modern sciences the human body was interpreted as a machine, with the effect that the "lived body" and bodily intentionality were ignored. The distinction between the human body as a purely material thing (Körper) and the lived body (Leib) as a source of intentionality and meaning conferral was covered over (see, e.g., Husserl 1970). The mind/body problem develops at the point at which the body is seen as an object of natural science, as purely objective, but the mind is not yet seen as an object of natural science. If the mind is still seen as subjective, even as a soul, then how could it possibly be related to the body? As the natural sciences are extended and augmented the human mind also comes to be seen in purely objective terms in various "sciences of the mind", e.g., as a machine.

Thus, we develop in the sciences an interpretive scheme the goal of which is to absolutely minimize subjectivity and to maximize objectivity and when we apply this interpretive scheme to the human mind we see that we achieve just this effect. The 
problem is that we are forgetting what this interpretive scheme abstracts from or leaves behind in the first place. It is not a foundation but is rather already a founded, reflective scheme that depends on making the abstractions we have noted (e.g., quantitative from qualitative features, primary from secondary qualities, form from content) and then forgetting about the whole from which they were abstracted. Hence, it can become a limited or one-sided view that conceals much that is important about human cognition. The key point is this: the claim that the human mind or body is the "object" of one of these sciences depends on the fact that human beings whose cognitive acts exhibit intentionality have developed a particular interpretive scheme in the first place, a scheme which they have then applied to themselves. We have, in effect, taken an important and fruitful interpretive scheme and applied it beyond its legitimate boundaries. In so doing, we substitute parts of what we are for the whole. At the founding level of all of this, however, we have human subjects with intentionality who build up ways of understanding the world through their manifold capacities for interpretation. The claim that human minds and bodies are to be understood only through such natural sciences rests on a development that presupposes the human capacity for meaning conferral, intentionality, directedness, acts of abstraction, and so on. Science itself is just a kind of directedness. It is a type of intentionality. Our awareness of our own consciousness, however, does not depend on building up layers of scientific theory, abstraction, idealization, and so on. At the prereflective, pre-scientific level humans are already conscious interpreters of the world who are directed toward various goals.

Among the features of human consciousness that should presumably be considered in the philosophy of mind but that tend to be concealed by the filtering required for natural science are the following: more detailed structural features of the intentionality of consciousness, the meaning-giving character of conscious experience, the perspectival character of consciousness, the inner and outer horizons associated with acts of consciousness, the figure/ground structure of consciousness, qualia, the temporal structure of consciousness with its retention-protention and secondary memory components, the underdetermination of perceptual observation by sensation, and so on.

Focusing on this example in the philosophy of mind, let us now come back to the questions posed I posed earlier on the relation of science to philosophy in analytic and Continental philosophy. Is natural science to be a model for philosophy of mind or not? Is it, in some sense, foundational, so that philosophy should be measured against it or, rather, is philosophy, properly conceived, a foundation for science? Is natural science limited and one-sided as a model for philosophy of mind or does it represent just the sort of regimentation we need in philosophy? Is natural science a condition for the possibility of legitimate philosophy or is philosophy in some sense a condition for the possibility of natural science?

The argument is that if we are to see things whole then we must keep both objectivity and subjectivity in the picture. The interpretive scheme involved in natural science provides us with a founded understanding of the world and there is a deeper, founding whole on which it depends. This deeper founding stratum of everyday 
practices and perception, as noted above, is called the "lifeworld" in Husserl's philosophy. There are prereflective and more immediate forms of understanding and knowing. These are forms of understanding and knowing that do not involve all of the abstractions of the interpretive scheme we have been discussing. Natural science has not always existed but it does not follow that human beings had no understanding or knowledge of anything prior to the development of natural science. On the view I am describing the interpretive scheme of the natural sciences is not foundational but is itself founded on our lifeworld experience. ${ }^{2}$ Natural science can make us blind to our own subjective experience. Thus, I am arguing against reductionism in this sense.

Skepticism about the claim that human consciousness is real or that human subjective qualitative states are real, for example, is skepticism gone too far. I think it is a false dilemma to claim that we must choose between pure objectivity and pure subjectivity. Surely there can be some objectivity about human subjectivity. We can presumably even arrive at objective claims about human consciousness that are not based on natural science. These would be claims about the structures of human consciousness that make natural science possible in the first place. For example, it seems to be invariant across different human subjects that human consciousness is perspectival, or that human beliefs exhibit intentionality. In the case of intentionality, what could it possibly mean to say that humans have beliefs but the beliefs are not about anything? Objective claims about human consciousness that are not based on natural science, such as statements about intentionality, the perspectival character of consciousness, the horizons of conscious acts, qualia, the temporal structure of consciousness, and so on, might very well involve generalization, abstraction, and perhaps even some idealization, but this seems to be inescapable if there is to be any theory or any philosophy of anything. The point is not to abandon theory or philosophy but to exercise a kind of skepticism about one-sided or reductionistic theorizing or philosophizing. We should also put a somewhat finer point on our remarks about science here. Some phenomenologists, for example, have followed Husserl in thinking that there can be an eidetic, apriori science of human consciousness, where the model of science does not stem from empiricism but rather from the tradition of rationalism. Objectivity about subjectivity on such a view would certainly involve abstraction, material a priori generalization from particular individuals, making essences salient through imaginative variation, and so on. Phenomenology, on this view, would not be a natural science but would be a material a priori science that is descriptive, primarily non-quantitative, not in search of causal explanation, and not engaged in formalization to any extent. It was already noted above how there are even parts of natural science that are descriptive, primarily non-

\footnotetext{
2 Thus one can also see why Continental philosophers who reflect on science often use language that differs from the language of science. Should we expect that which is presupposed by a science to be expressed in the language of that science? Generally, should we expect a statement of the conditions for the possibility of science to use the language of science? It is a further matter, however, just what kind of language is appropriate at the founding level. One sees wide ranging differences on this matter within Continental philosophy. My own view is that obscurantism in philosophy is not very helpful, but I won't go into the issues here.
} 
quantitative, not in search of causal explanation, and not engaged in formalization to any extent. Natural science, however, cannot be construed as a material a priori or eidetic science. ${ }^{3}$ Many Continental philosophers in Husserl's wake, however, abandoned his idea of phenomenology as eidetic science. Indeed, the model of 'scientific' philosophy in any form was rejected.

\section{CONSTRUCTIVE ENGAGEMENT OF ANALYTIC AND CONTINENTAL PHILOSOPHY?}

Although I have focused on some particular issues about natural science and consciousness, one could consider many other kinds of examples. Suppose we ask, for example, whether biological evolution makes the human mind possible. According to our best scientific theory on the matter, the theory of evolution, the answer of course is 'yes'. The argument we are considering can be construed as agreeing with this and then adding that we should nonetheless not forget that the human mind makes the theory of evolution possible in the first place. Certain features of human cognition, as just suggested, are presupposed by the existence of any theory whatsoever. These features are, in this sense, a condition for the possibility of theory construction. What would these prior ('a priori') conditions be? It seems to me to be perfectly legitimate to hold that it is the business of philosophy to explore this question. We can say the same thing about each of our best scientific theories.

I think there can be no doubt that the engagement between analytic and Continental philosophy has at times been destructive. It has had its episodes of bitterness, exclusion, power politics, and so on. Do I think constructive engagement between analytic and Continental philosophy on the relation of science to philosophy is possible? Yes. This is possible not only in philosophy of mind but also in other areas in which differences have been manifest. It may not be an easy problem to overcome (consider again the quotations in Section 1 of this paper), but if we can see more clearly into our own philosophical past in the twentieth century then we can perhaps make more progress in fostering constructive engagement and balance between at least some elements of these traditions. Indeed, a number of the featured speakers in the Center for Comparative Philosophy Symposium for which this paper was written have fostered such constructive engagement over the years: Dagfinn Føllesdal has done this in connection with ideas of Quine and Husserl, Hubert Dreyfus is known for his work on the relation of Heidegger to artificial intelligence and cognitive science, and John Searle has worked on intentionality and philosophy of language. There are now many other instances of such cross-tradition engagement. In the past few decades there has been a significant postanalytic turn within analytic philosophy as well as an analytic turn in parts of Continental philosophy. This signifies progress, in my view. Not only is it good to try to prevent wars but the interactions have been fruitful in many ways.

\footnotetext{
${ }^{3}$ For more on the distinction between material a priori science and material a posteriori science see, e.g., Chapter 1 of Tieszen 2005.
} 


\section{THE PLACE OF NATURAL SCIENCE IN GLOBAL PHILOSOPHY}

The split between analytic and Continental philosophy is a relatively recent phenomenon in the tradition of Western philosophy. What bearing, if any, does it have on comparative philosophy in a broad sense, and on the prospects for constructive engagement between widely varying philosophical traditions? What implications might it have for philosophy in traditions such as those associated with China, India, the Middle East, Latin America, Africa, and so on? I think that the issues that have been raised about the relation of natural science to philosophy in analytic and Continental philosophy are certainly relevant to and important for comparative philosophy in a broader sense. Western philosophy has been deeply influenced by science and technology but there have also been reactions against this influence in some quarters in Western philosophy. This dynamic is still being played out. Philosophy in other parts of the world has arguably not yet engaged with science and technology to the same extent, although this is happening more and more as time passes. What is the appropriate relation of natural science to philosophy? Some interesting and important answers to this question have already been thematized and developed in the interactions between analytic and Continental philosophy.

Science and technology have affected our world profoundly and they will continue to do so. The investigation of relation of natural science to philosophy in a global context is a large topic in its own right, but let me just briefly mention two further examples to give an indication of what I have in mind. It would be possible to choose many such examples.

Example 1 -- Daoism Meets Natural Science. One of my favorite texts in Chinese philosophy is the Dao-De-Jing. Now what is the appropriate relation of natural science to philosophy when natural science meets a philosophical and poetic text such as the Dao-De-Jing? The Wing-Tsit Chan translation of Chapter 1 of the Dao-DeJing reads as follows ${ }^{4}$ :

The Tao that can be told of is not the eternal Tao;

The name that can be named is not the eternal name.

The Nameless is the origin of Heaven and Earth;

The Named is the mother of all things.

Therefore let there always be non-being, so we may see their subtlety,

And let there always be being, so we may see their outcome.

The two are the same,

But after they are produced, they have different names.

They both may be called deep and profound.

Deeper and more profound,

The door of all subtleties!

${ }^{4}$ The English translations of the Dao-De-Jing vary widely. For an interesting perspective on this, with an alternative translation of the first sentences of Chapter 1 of the Dao-De-Jing, see my colleague Bo Mou's 2003. 
I think that many philosophers would take this passage to have more in common with certain types of Continental philosophy than it does with types of analytic philosophy. Be that as it may, what is the appropriate relation of natural science to this kind of philosophy? Presumably natural science should not be or is not in a position to dismiss such a philosophical text with a lordly wave of the hand. Perhaps we need to exercise some skepticism about science as "the Grand Narrative" (in Derrida's colorful but derisive phrase). One might be worried about what remains of the passage if we measure it against the standards of natural science that were spelled out in Section 3 above, such as empirical verification, limitation to primary qualities that can be quantified and formalized, preference for form over content, preference for exact language, and so on. As we argued in Sections 3 and 4, the conditions (1)-(7) provide a founded interpretation of the world that starts with sense experience and then abstracts, idealizes, quantifies, formalizes, and possibly mechanizes. It is an interpretation that provides a certain perspective on the world. It has been argued that such an interpretive scheme reveals many remarkable facts about the world but that we must also be careful about what it might conceal. The interactions that have taken place between analytic and Continental philosophy suggest that we need to take care not to forget about the whole from which the interpretation was abstracted. Are there important perspectives on the world that might be concealed or forgotten if we adopt the interpretive scheme of the natural sciences? Should we not be careful about slipping into an eliminative reductionism here? These are all points have been made and discussed in the literature on the place of science in analytic and Continental philosophy. Heidegger even says at one point that "...perhaps ancient traditions of thought will awaken in Russia or China which will help man achieve a free relationship to the technological world" (Heidegger 1977). It is known that Heidegger studied the Dao-De-Jing.

Example 2 - Buddhism Meets Natural Science. What happens, for example, when philosophical views such as logical positivism or neuroscientific reductionism meet Buddhist philosophy? It is not clear to me that one could expect the engagement in this case to be constructive. Is Buddhist philosophy to be measured by the standards of science? Is natural science to be dismissed in Buddhist philosophy? The point is that Buddhism would do well not to be subject to natural science in the way that some forms of analytic philosophy have become subject to natural science. I am not arguing that Buddhist philosophy should forget about or turn its back on natural science. On the other hand, the strong anti-scientific or obscurantist aspects of some types of Continental philosophy are also not very helpful. A good example of an effort to find the right balance here can be found in the some of the work of the Fourteenth Dalai Lama, such as his book The Universe in a Single Atom. ${ }^{5}$ The Dalai Lama is very open to science but he evidently feels that while science can perhaps correct Buddhism in certain respects (e.g., Abhidharma cosmology) it is not in a position to overrule

${ }^{5}$ I am thinking also of his participation in the "Mind and Life" conferences, and spinoffs such Hayward and Varela 2001. 
Buddhist ideas on all matters. On Buddhist views on consciousness, for example, he says

Even from this brief discussion, it is, I think, clear that the third-person method-which has served science so well in so many areas-is inadequate to the explanation of consciousness. What is required, if science is successfully to probe the nature of consciousness, is nothing short of a paradigm shift. That is, the third-person perspective, which can measure phenomena from the point of view of an independent observer, must be integrated with a first-person perspective, which will allow the incorporation of subjectivity and the qualities that characterize the experience of consciousness.

A comprehensive scientific study of consciousness must therefore embrace both thirdperson and first-person methods: it cannot ignore the phenomenological reality of subjective experience but must observe all the rules of scientific rigor. So the critical question is: Can we envision a scientific methodology for the study of consciousness whereby a robust first-person method, which does full justice to the phenomenology of experience, can be combined with the objectivist perspective of the study of the brain?

Here I feel a close collaboration between modern science and the contemplative traditions such as Buddhism, could prove beneficial. (The Dalai Lama 2005, 133-4)

In my view, the combination of the first-person method with the third-person method offers the promise of a real advance in the scientific study of consciousness. (The Dalai Lama 2005, 142)

These ideas are remarkably similar to some of the points about science that have emerged in interactions between analytic and Continental philosophers.

\section{CONCLUSION: THE NEED FOR BALANCE}

Our brief reflections on analytic and Continental philosophy, science, and global philosophy show how we can avoid the view according to which the sciences and technology provide the fundamental or only ways of knowing, understanding, and being in the world, and that value natural science and technology above all else. If we should avoid such a scientism it does not at all follow that we should avoid science. It is rather just a matter of keeping it in its proper place. Natural science reveals and conceals. I think the idea would be to retain and develop what is revealed by the sciences, subject to critical scrutiny, responsibility, and broader values, but also to cultivate our understanding of the fundamental features of experience that are concealed by the sciences, where this is also subject to critical scrutiny, responsibility, and broader values.

What we arguably need, therefore, is a kind of balance. We do not want to reject science but, rather, we would like to develop the right kind of relationship to it. We need to get it in perspective. To put it in perspective is at the same time to see its limits. On the one hand, there is a tendency toward scientism in many forms of analytic philosophy. If scientism is the view that it is only through science and technology that we have knowledge or understanding of anything then it is an 
exclusionary view. There is a kind of reductionism at work in some quarters of science in which anything not reducible to scientific knowledge is to be rejected. Of course one can be more or less hard-nosed about this but there are in fact some very hard noses out there. A scientific understanding of Being (or non-Being) on which one embraced the abstractions inherent in the scientific worldview and then either forgot about or covered over what was left behind by the abstractions is, by intention or not, a kind of eliminative reductionism. It is a reductionism that can be understood in terms of the part-whole scheme outlined above.

On the other hand, the ideas I have expressed do not imply that we ought to rebound into an anti-scientific or anti-technology stance. Science and technology, in addition to having the potential to provide enormous practical benefits to humanity, can provide an important corrective to the many possible interpretations of the world that involve superstition, credulousness, religious intolerance, and the like. Science and technology can instill a healthy skepticism. Skepticism about the claims that the earth is flat or that the universe is only several thousand years old, for example, is a healthy skepticism. A scientific worldview can also, however, issue in an unhealthy skepticism that would have us deny a place for other important features of our world.

\section{ACKNOWLEDGEMENTS}

A shorter version of this paper was originally presented as an invited lecture at the April 10, 2010, Symposium on Constructive Engagement of Analytic and Continental Approaches in Philosophy, sponsored by the Center for Comparative Philosophy at San José State University. I am grateful to the speakers and audience members for their comments and questions. I also thank three anonymous referees of Comparative Philosophy for their insightful comments on an earlier version of the paper.

\section{REFERENCES}

Carnap, R. (1959), "The Elimination of Metaphysics Through the Logical Analysis of Language". Originally published in German in 1931. English translation by A. Pap in A.J. Ayer (ed.), Logical Positivism (Glencoe, IL: The Free Press), 60-81.

---- (2002), The Logical Syntax of Language (La Salle, IL: Open Court). Originally published in German in 1934. English translation by A. Smeaton.

Dalai Lama (2005), The Universe in a Single Atom (New York: Broadway Books).

Dummett, M. (1994), Origins of Analytic Philosophy (Cambridge, MA.: Harvard University Press).

Friedman, M. (2000), A Parting of the Ways: Carnap, Cassirer, and Heidegger (La Salle, IL: Open Court).

Gödel, K. (1961), "The Modern Development of the Foundations of Mathematics in the Light of Philosophy", in Kurt Gödel: Collected Works, Vol. III (Oxford: Oxford University Press), 374-87. 
Hayward, J. and Varela, F. (2001), Gentle Bridges: Conversations with the Dalai Lama on the Sciences of Mind (Boston: Shambhala).

Heidegger, M. (1977), "Only a God Can Save Us Now", Graduate Faculty Philosophy Journal, 6: 5-27. This is an English translation by D. Schendler of a 1966 Der Spiegel interview with Heidegger.

---- (1977), “What Is Metaphysics?”, in D.F. Krell (ed.), Martin Heidegger: Basic Writings (New York: Harper \& Row), 95-112. Originally delivered in German in 1929 as an inaugural lecture at Freiburg University. English translation by D.F. Krell.

Husserl, E. (1970), The Crisis of the European Sciences and Transcendental Phenomenology (Evanston, IL: Northwestern University Press). Originally published in German in 1936. English Translation by D. Carr.

Lao Zi (1963), Tao Te Ching (Indianapolis, IN: Bobbs-Merrill). English translation by Wing-Tsit Chan.

Mou, Bo (2003), "Eternal Dao, Constant Name, and Language Engagement”, in B. Mou (ed.), Comparative Approaches to Chinese Philosophy (Aldershot, United Kingdom: Ashgate), 245-62.

Quine, W. V. O. (1960), Word and Object (Cambridge, MA.: MIT Press).

Sokal, A., and Bricmont, J. (1998), Fashionable Nonsense: Postmodern Intellectuals' Abuse of Science (New York: Picador).

Sokal, A. (2010), Beyond the Hoax: Science, Philosophy and Culture (Oxford: Oxford University Press).

Tieszen, R. (2005), Phenomenology, Logic, and the Philosophy of Mathematics (Cambridge: Cambridge University Press).

----(2011), After Gödel: Platonism and Rationalism in Mathematics and Logic (Oxford: Oxford University Press).

Wang, H. (1996), A Logical Journey: From Gödel to Philosophy (Cambridge, MA.: MIT Press). 